\title{
SICAK-NEMLİ İKLİMLERDEKİ KONUT BİNALARINDA GECE HAVALANDIRMASI PERFORMANSININ ANALIZİ
}

\author{
Yusuf YILDIZ \\ Balıkesir Üniversitesi, Mimarlık Bölümü, Çağış Kampüsü, 10145, Balıkesir, Türkiye \\ yusifyildiz@gmail.com
}

(Geliş/Received: 19.12.2012; Kabul/Accepted: 15.05.2014)

ÖZET

Gece havalandırması yaygın kullanılan pasif soğutma tekniklerinden biridir ve literatürde bu konuda yapılmış çeşitli teorik ve deneysel çalışmalar mevcuttur. Ancak iklim değişikliğinin etkisi çok fazla dikkate alınmamıştır. Gece havalandırmasından alınacak verimlilik, küresel ısınmadan kaynaklanabilecek dış hava sıcaklığındaki artışa bağlı olarak değişebilir çünkü küresel ısınma, binalarda soğutma gereksiniminin artmasına neden olabilir. Bu çalışmada, İzmir'de bulunan bir apartman binasında yapılabilecek gece havalandırmasının soğutma yüküne etkisi ve performansına küresel ısınma ile birlikte yalıtım yeri ve hava değişim hızı oranının etkisi simülasyon programı kullanarak incelenmiş̧ir. Sonuç olarak iklim değişikliğine rağmen sıcak-nemli iklimlerde gece havalandırması ile soğutma yükünün ortalama $\% 13$ azalabileceği fakat katkısının zaman içinde azaldığı görülmüştür.Ayrıca, gece havalandırması performansı üzerinde hava değişim hızı oranının önemli bir etkiye sahip olduğu ve dış duvarlarda yalıtım yerinin kritik bir etkisinin olmadığı bulunmuştur.

Anahtar kelimeler:Küresel ısınma, sıcak-nemli iklimler, pasif soğutma, gece havalandırması, konutlar

\section{ANALYSIS OF PERFORMANCE OF NIGHT VENTILATION FOR RESIDENTIAL BUILDINGS IN HOT-HUMID CLIMATES}

\begin{abstract}
Night ventilation is one of the passive cooling techniques commonly used and various theoretical and experimental studies on this subject are available in the literature. However, the effects of climate change are not taken into account. The efficiency of night ventilation can change based on the increasing outside air temperature, which can be caused by global warming because global warming can lead to increase cooling demand in buildings. In this study, impact and performance of night ventilation on cooling load is examined based on location of insulation layer and air exchange rate in an apartment block located in Izmir under climate change by using simulation tool.As a result, it is seen that cooling load in hot-humid climate can be reduced by $13 \%$ with night ventilation in spite of climate change but its contribution has decreased over time. Meanwhile, air exchange rate has a significant impact on performance of night ventilation and location of insulation layer on outside walls has been found to have non critical effect.
\end{abstract}

Keywords: Global warming, hot-humid climate, passive cooling,night ventilation, residential building

\section{GİRIŞ (INTRODUCTION)}

Küresel isınmadan kaynaklanan dış sıcaklılardaki kademeli artış, özellikle sıcak-nemli iklimlerde yer alan binalarda soğutma yükü artışına neden olabilir. Buna ek olarak yüksek soğutma ihtiyacı, daha fazla sera gazı salınımına yol açabilir ve dolayısıyla küresel 1sınma sürecini destekleyebilir [1]. Bu yüzden yeni ve mevcut binalarda soğutma amaçlı enerji tüketimini azaltmak amaciyla enerji etkin tedbirler uygulanmalıdır. Aksi taktirde klima kullanımı artmaya devam edebilir.

Pasif soğutma teknikleri, binalarda soğutma yükünü başka bir ifadeyle soğutma için gerekli enerji tüketimini azaltmak için kullanılabilir [2-3]. Pasif soğutma tekniklerinin etkinliği genellikle yerel iklim özelliklerine bağlıdır [4]. Bu nedenle pasif soğutma tekniklerine karar verirken iklim değişikliğinin etkileri dikkate alınmalıdır. Yaygın olarak kullanılan 
pasif soğutma yöntemlerinden bir tanesi yaz aylarında daha az soğutma ve kabul edilebilir bir iç ortam oluşturmak için uygulanan gece havalandırmasıdır [5].Gece havalandırması binalarda ertesi gün, bir serinlik oluşturması için zorlanmış, doğal veya hibrid (iki sistemin birleşimi) havalandırma ile yapılabilir [6-7]. Ayrıca pasif ev kavramı içinde yer alan doğal havalandırma kullanımı, günümüzde enerji, çevre ve iç hava kalitesi ile ilgili sorunların artması nedeniyle ön plana çıkmaktadır [8-9].

Birçok araştırmacı gece havalandırması üzerine teorik ve deneysel araştırmalar yapmıştır.Bunlara ek olarak, gece havalandirmasinın performansinı etkileyen parametreler belirlenmiştir. Artmann ve arkadaşları [5] gece havalandırmasının soğutma açısından bütün Avrupa da önemli bir potansiyele sahip olduğunu göstermiştir. Geros ve arkadaşları [10] ise Yunanistan'ın Atina kentindeki 10 farklı kentsel kanyonda gece havalandırmasının verimini incelemiştir. Finn ve arkadaşları [11] deniz tipi iklimde (Maritimeclimate) bulunan bir kütüphane binasında gece havalandırması için tasarım ve operasyonel parametrelerin rolünü araştırmıştır ve havalandırma oranı ve iç kazançların ısıl konfor üzerinde önemli bir etkiye sahip olduğu bulunmuştur. Artmann ve arkadaşları [12] gece havalandırması performansının ayrıca iklim koşullarından ve ısıl kütleden etkilendiğini belirlemiştir. Binalarda kullanıcı alışkanlıkları örneğin pencereleri açıp kapatmaları gece havalandırması performansını etkilemektedir [13]. Ayrıca, 1sıl kütlenin gece havalandırması performansı üzerindeki etkisi çeşitli araştırmacılar tarafından incelenmiştir [14-15-16]. Santamouris ve arkadaşları [17] 214 konut binasından veri toplayarak binaların soğutma ihtiyacı ile gece havalandırmasının soğutmaya katkısı arasındaki ilişkiyi araştırmıştır. Elde edilen sonuçlar soğutma ihtiyacinın yüksek olduğu binalarda gece havalandırmasının katkısının daha fazla olduğunu göstermiştir. Kubota ve arkadaşları [18] konut binalarında gece havalandırması etkinliğini bir anketle değerlendirmiş ve önemli derecede 1sıl konfora katkı sağladıkları görülmüştür. Fraisse ve arkadaşları [6] gece havalandırmasının havalandırılan çift cidarlı cephe kullanarak uygulanabilirliğini incelemiştir. Havalandırılan çift cidarlı cephe nedeniyle özellikle ahşap çerçeveli evlerde ısıl konfor koşullarına daha kolay yaklaşıldığı görülmüştür.Özetle yapılan birçok çalışmada kamu ve ticari binalarda gece havalandırmasının etkisi incelenmiştir.

$\mathrm{Bu}$ çalışmada, Türkiye de sıcak-nemli iklim bölgesindeki apartman binalarında gece havalandırmasının soğutma yükü üzerindeki etkisi yalıtımın yeri, hava değişim hızı ve iklim değişikliğine bağlı olarak değerlendirilmektedir. Özellikle konut binaları üzerinde durulmaktadır çünkü Türkiye de yapı stokuna bakıldığında konut binalarının ağırlıkta olduğu görülmektedir ve yapılan çalışmalarda konut binaları azınlıkta kalmaktadır.
Çalışmanın temel amacı, sıcak-nemli iklim bölgesindeki apartman binalarında gece havalandırmasından elde edilecek performansın 2020, 2050 ve 2080 yıllarında nasıl değiştiğini incelemektir. Ayrıca dış duvarlarda yalıtımın yeri ve hava değişim hızının performans üzerindeki etkisini ve zaman içindeki değişimini görmektir.Elde edilen sonuçlar 1şığında konutlarda gece havalandırması uygulamalarından daha fazla performans elde edilebilir. Bu çalışmada sadece sıcak-nemli iklim dikkate alınmıştır fakat izlenen yöntem diğer iklim tipleri için kolayca uygulanabilir.

\section{YÖNTEM (METHOD)}

$\mathrm{Bu}$ bölümde, ilk olarak İzmir'de bulunan mevcut apartman binasının genel özellikleri tanımlanmıştır ve dış duvarlarda yalıtım yeri için değişik varyasyonlar belirlenmiştir. Daha sonra seçilen binanın ısıl modeli gerekli kabuller yapılarak hazırlanmıştır. İzmir için gelecek saatlik iklim bilgileri Tipik Meteorolojik Yil (TMY) verileri kullanılarak oluşturulmuştur.Salonda iç sıcaklıklar ölçülerek analiz edilmiştir. Daha sonra ise enerji simülasyon programı EnergyPlus kullanılarak gece havalandırması performansına yalıtım yeri, hava değişim hızı ve iklim değişikliğinin etkisi incelenmiştir.

\subsection{Seçilen Binanın Genel Özellikleri(General Features of SelectedApartmentBuilding)}

Seçilen apartman binası 8 katlı olup her katta üç daire bulunmaktadır (Şekil 1). Daireler yaklaşık $110 \mathrm{~m}^{2}$ ' dir ve salon, mutfak, üç yatak odası, banyo ve tuvaletten oluşmaktadır. Apartman binası 1990 yılında inşaa edilmiştir. $\mathrm{Bu}$ yıllarda Binalarda Isı Yalıtım Yönetmeliği zorunlu olmadığından binada çatı haricinde yeterli 1s1 yalıtımı yoktur. Tablo 1'de yap1 elemanlarının toplam isı geçirgenlik katsayıları verilmiştir.

\subsection{Dıș Duvarlarda Isı Yalıtım Yeri için Varyasyonlar Oluşturulması(Generation of VariationsforLocation of ThermalInsulation on ExternalWalls)}

Isı yalıtımı, binalarda enerji korunumu açısından öncelikli olarak düşünülmesi gereken önlemler arasındadır [19] ve yapı elemanında yalıtımın yeri enerji performansinı etkileyen faktörlerden bir tanesidir. Başka bir deyişle aynı katmanlardan oluşan yap1 elemanı, katmanların dizilişlerine göre enerji korunumu açısından daha fazla veya daha az yarar sağlayabilir [20]. Bu nedenle dış duvarlarda yalıtım yerinin gece havalandırması üzerindeki etkisi incelenmiştir. Toplam 1sı geçirgenlik katsayıları (U: $0,59 \mathrm{~W} / \mathrm{m}^{2} \mathrm{~K}$ ) aynı olmak koşulu ile üç farklı varyasyon belirlenmiştir (Şekil 2): v1 1sı yalıtımı duvarın diş yüzeyinde, v2 1sı yalıtımı iki duvarın ortasında ve v3 1sı yalıtımı duvarın iç yüzeyinde. Belirlenen bu varyasyonlar Türkiye de yapı sektöründe yaygın şekilde uygulanmaktadır. 


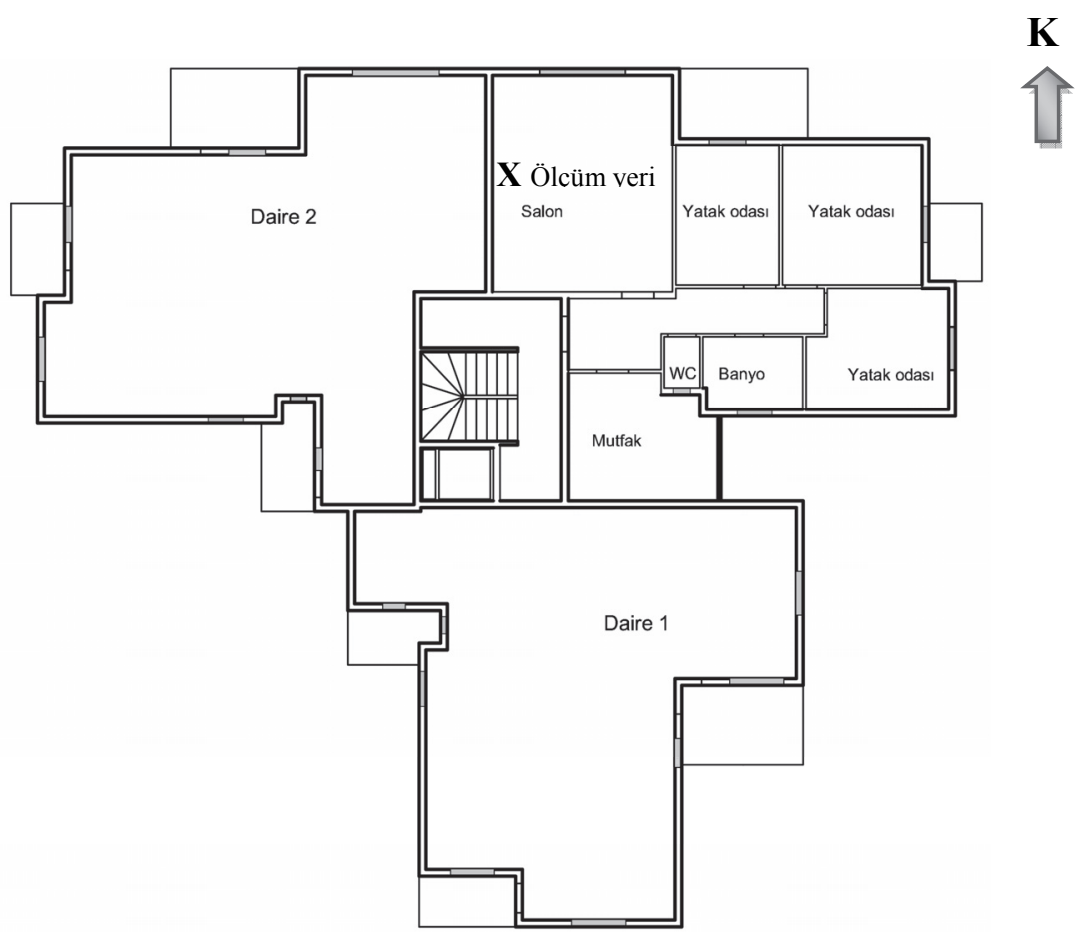

Şekil 1. Apartman binasının normal kat planı (Plan of apartmentbuilding)

Tablo 1. Yapı elemanlarının toplam 1sı geçirgenlik katsayıları(Overall heat transfer coefficients of construction layers)

\begin{tabular}{llc}
\hline Yapı elemanı & Katmanlar & $\mathbf{U}\left(\mathbf{W} / \mathbf{m}^{\mathbf{2}} \mathbf{K}\right)$ \\
\hline Diş duvar & Sıva, tuğla, sıva & 1.41 \\
İç duvar & Sıva, tuğla, sıva & 1.41 \\
Çatı & Sıva, betonarme döşeme, cam yünü, çatı kaplaması & 0.83 \\
Zemin & Kaplama, zemin döşemesi, grobeton & \\
Pencere & Çift cam (6mm/13mm-hava) & 2.70 \\
& & \\
\hline Pencere & Güneşten ısı kazanç katsayısı & 0.71 \\
\hline
\end{tabular}
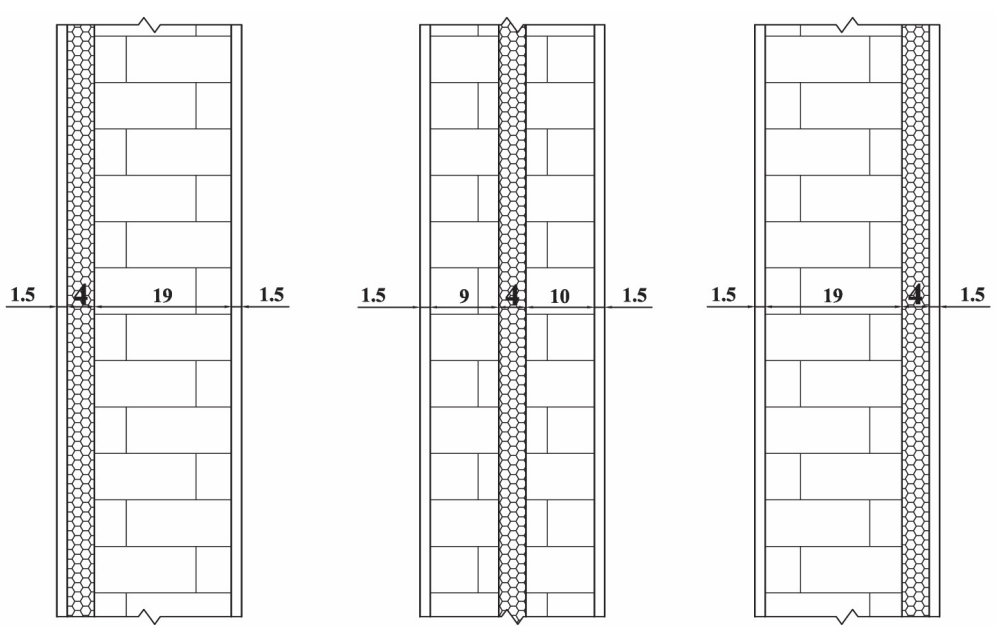

Şekil 2. Dış duvarda 1Sı yalıtım varyasyonları(Variations of thermal insulation on external walls)

Mevcut apartman binasının dış duvarlarında herhangi bir 1sıyalıtımı olmadığından $4 \mathrm{~cm}$ Ekstürüdepolisitren köpük kullanılmıştır. TS 825 1sı yalıtım standard1 dikkate alınarak yalıtım kalınlığı hesaplanmıştır.

\subsection{Simülasyon Modeli (Simulation Model)}

Günümüzde çok sayıda enerji analiz programı mevcuttur fakat özellikle ülkemizde binaların performans analizi için hala yeterli ölçüde kullanılmamaktadır. $\mathrm{Bu}$ çalışmada, apartman binasının geometrik modeli ve termofiziksel bilgileri 
DesignBuilder v2.04. kullanarak hazırlanmıştır. DesignBuilder tüm hesaplamalar için EnergyPlus programını kullanan gelişmiş bir ara yüz yazılımdır. Birçok işlemi EnergyPlus programını kullanmadan yapabilmeye olanak sağlar. Detaylı performans analizinde direkt olarak EnergyPlus programının kullanılmasında fayda vardır. Amerika Birleşik Devletleri Enerji Bakanlığı tarafından geliştirilen EnergyPlus programı zaman içinde gelişerek en yaygın ve güçlü bina enerji modelleme araçlarından biri haline gelmiştir [21]. EnergyPlus programı ile 1sıtma, soğutma, aydınlatma, havalandırma amaçli enerji tüketimleri, 1sıl konfor hesaplamalar1, karbondioksit salınımları vb. hesaplamalar yapılabilir. Bu çalışmada, seçilen apartman binasının sadece soğutma yükü hesaplanmış ve değerlendirilmiştir. $\mathrm{Bu}$ nedenle soğutma sistemi ve çalışma saatleri dikkate alınmıştır. İzmir iklimi göz önüne alınarak soğutma dönemi Nisan ve Eylül ayları arası olduğu ve soğutma termostat derecesi ASHRAE standard1 55-2010'a [22] göre $26{ }^{\circ} \mathrm{C}$ olarak kabul edilmiştir. İzmir'deki apartman binalarına bakıldığında soğutma için bireysel split klimaların kullanıldığı görülmektedir. $\mathrm{Bu}$ nedenle klimaların gün içinde ne zaman kullanılacağını sistematize etmek çok zordur. Kullanıcı profiline göre değişkenlik gösterebilir. $\mathrm{Bu}$ nedenle apartman binasının genel soğutma yükünü incelemek daha uygun olacaktır ve klimaların gün içinde sabah saat 9 akşam 24 arası çalıştığı kabul edilmiş soğutma yükü buna göre simüle edilmiştir. Dairelerde tek çocuklu aile yaşadığı varsayılmıştır. İstenmeyen hava kaçak oranının 0,8 ach olduğu kabul edilmiştir.

Apartman binasının termal modeli oluşturulduktan sonra gece havalandırması için gerekli bilgiler programa girilmiştir. Gece havalandırmasının gece saat 1 ve 6 saatleri arasında yapılması tercih edilmiştir çünkü İzmir'in gece dış hava sıcaklığı yaklaşık bir yıl süreyle ölçülmüştür ve incelendiğinde genel olarak belirlenen saatler arasında en düşük olduğu görülmüştür. Gece havalandırması dairelerde, mevcut pencereler gece 1 ve 6 saatleri arasında açılarak yapılmıştır ve gece havalandırmasının soğutma yüküne etkisi hava değişim hızı 2, 4 ve 6 ach değerleri için analiz edilmiştir.

\section{4. İzmir İklimi ve Gelecek İklim Verisi(Climate of IzmırandFutureClimate Data)}

İzmir, Ege Bölgesi'nde bulunan Türkiye'nin 3. Büyük kentidir ve sicak-nemli iklim bölgesinde yer almaktadır; kışları 1lık ve yağıșlı, yazları ise sıcak ve nemlidir. Yıllık ortalama diş sıcaklıklar $16,08^{\circ} \mathrm{C}$ 'dir. Minimum sicaklıklar $\left(5,7^{\circ} \mathrm{C}\right)$ genellikle Ocak ayında, maksimum sicaklıklar $\left(33^{\circ} \mathrm{C}\right)$ ise Temmuz ayında gerçekleşmektedir. Yıllık ortalama bağll nem ise $\% 64,58$ 'dir [23].

Enerji modellemesi yapan programlar, hesaplamalar için saatlik iklim verilerine ihtiyaç duymaktadırlar. Bu nedenle İzmir'in iklimsel özelliklerini yansıtan bir yıllık saatlik iklim verisi gereklidir. Bu çalışmada İzmir için var olan Amerika Birleşik Devletleri Enerji Bakanlığı tarafından enerji modellemesi programları için hazırlanmış Tipik Meteorolojik Yıl (Typical Meteorological Year) verileri kullanılmıştır. Tipik Meteorolojik Yil en genel anlamıla bir yıldan daha fazla sürede oluşturulmuş bir veri bankasından belirli bir konum için seçilen o yerin genel iklimsel karakterini en iyi şekilde yansıtan uzun yıllar meteorolojik verilerinin harmanlanmasıdır [24].

Küresel ısınmanın gece havalandırması üzerindeki etkisini görebilmek için gelecek iklim öngörülerine dayanarak oluşturulmuş saatlik iklim verilerine ihtiyaç duyulmaktadır. Bunu oluşturabilmek için global iklim modeli olarak da bilinen genel sirkülasyon modelleri kullanılmaktadır. Yaygın olarak kullanılan genel iklim modellerinden bir tanesi İngiltere Meteoroloji Servisi Handley İklim Tahmin ve Araştırma Merkezi tarafından geliştirilen üçüncü nesil Atmosferik Dolaşım Modeli HadCM3'dür [25]. $\mathrm{Bu}$ çalışmada HadCM3'ün çıktıları kullanılmıştır. Ayrıca gelecek iklim öngörüsü yapabilmek için gaz salınım emisyon senaryolarına ihtiyaç vardır. Farklı kabullere göre İklim Değişikliği Hükümetlerarası Paneli (IPCC) tarafından çeşitli senaryolar geliştirilmiştir. $\mathrm{Bu}$ çalışma için IPCC'nin A2 senaryosu seçilmiştir. Geliştirilen senaryolar en kötümserden en iyimsere doğru siralandığında, A2 senaryosu en kötümser senaryodan bir önce gelmektedir. Dünyadaki büyüme ve gelişmenin bölgelere göre farklılık göstereceğini ve yavaş olacağını, nüfusun önemli ölçüde artacağını yani heterojen bir dünya olacağını varsayar [26]. A2 senaryosu A2a, A2b, ve A2c isimli üç alt senaryodan oluşmaktadır. Bu senaryolar iklim değişikliği sinyali üzerindeki yıllık iklim değişkenliğinin etkilerini ifade eder. Daha sonra bu üç senaryonun ortalamalarına göre 2020 (2010-2039), 2050 (2040-2069) ve 2080 (2070-2099) yıllarına ait İzmir için saatlik iklim verileri "Morphing" metodu ile CCWorldWeatherGen V1.5 programı kullanılarak oluşturulmuştur [27]. CCWorldWeatherGen araci Southampton Üniversitesi,İnşaat mühendisliği ve Çevre Okulu'nda bulunan Sürdürülebilir Enerjiler Araştırma Grubu tarafından hazırlanmıştır. Morphing metodu gözlenen iklim verileri ile gelecek iklim modelleri sonuçlarının birleştirilmesine dayanmaktadır [28]. Şekil 3'de İzmir için aylık ortalama dış sıcaklıklar, bağıl nem ve direk güneş radyasyonu değerleri baz yıl (TMY 2), 2020, 2050 ve 2080 yılları için verilmiştir. Tablolara bakıldığında ortalama sıcaklıklar ve direk güneş radyasyonunda artış, bağıl nemde ise zaman içinde azalma eğilimi görülmektedir.

\subsection{Yaz Döneminin İzlenmesi (Monitoring of SummerPeriod)}

İzmir'de en sicak aylardan bir tanesi olan Temmuz ayı boyunca seçilen apartman binasının en üst katındaki 
daire salonun da iç sıcaklıklar ölçülmüştür. Ayrıca aynı anda karşılaştırma yapabilmek için diş sıcaklıklarda kaydedilmiştir. İç ve dış sıcaklıklar hassasiyeti $\quad \pm 0,7 \quad{ }^{\circ} \mathrm{C}$ olan $\mathrm{HOBO}$ RH/Temp/Light/Externaldatalogger ile ölçülmüştür.
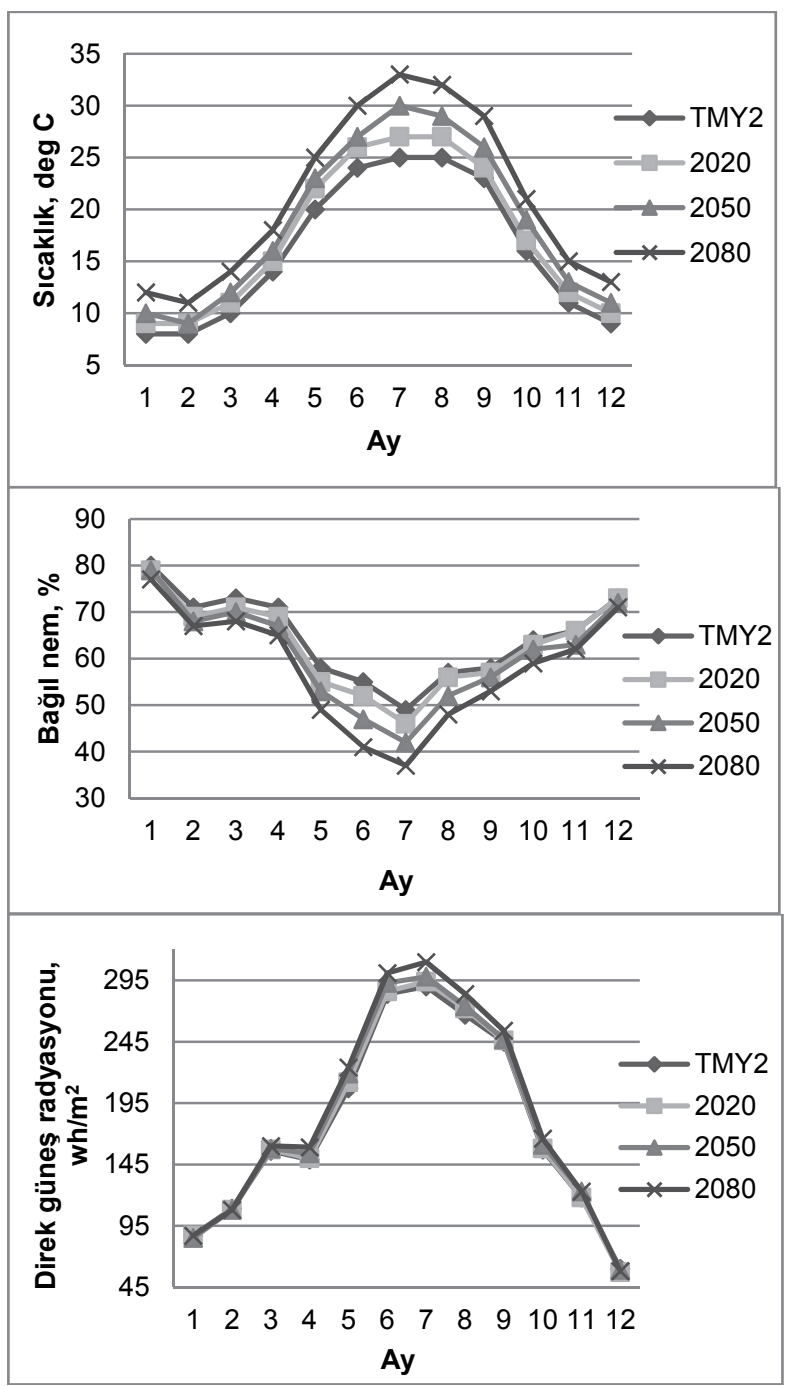

Şekil 3. Aylık ortalama dış sıcaklık, bağıl nem ve direk güneş radyasyon değerleri (baz yıl, 2020, 2050 ve 2080)(Monthly outdoor temperature, relative humidity and direct solar radiation (Base year, 2020s, 2050s and 2080s))

Veri kaydedici zeminden 1,5 m yukarıya direkt güneş ışınlarına maruz kalmayacak şekilde yerleştirilmiştir. Ölçüm aralığı ise 10 dakika olarak ayarlanmıştır. Ölçüm yapılan zaman aralığında klima kullanılmamıştır. Ölçüm sonuçlarına göre (Şekil 4), salonda temmuz ayı boyunca sicaklıklar $24,7{ }^{\circ} \mathrm{C}$ ile $34,2{ }^{\circ} \mathrm{C}$, dişarıda ise $24,8{ }^{\circ} \mathrm{C}$ ile $37{ }^{\circ} \mathrm{C}$ arasında değişmiştir. Ortalama sicaklıklar ise birbirine çok yakındır; salonda $31,5{ }^{\circ} \mathrm{C}$, dışarıda ise $31,9{ }^{\circ} \mathrm{C}$ 'dir. Bunun en önemli nedenleri arasında mevcut apartman binasının yeterli 1s1 yalıtımına sahip olmaması gösterilebilir.

\section{BULGULAR VE TARTIŞMA (RESULTS AND DISCUSSIONS)}

Gece havalandırmasının performansı seçilen apartman binasının $\mathrm{m}^{2}$ başına düşen yıllık soğutma yükündeki (Haziran, Temmuz ve Ağustos) değişime bağlı olarak değerlendirilmiştir. Baz alınan TMY 2 iklim verilerine göre, gece havalandırması olmadığı ve dıştan yalıtımlı durumunda apartman binasının soğutma yükü $17,39 \mathrm{kWh} / \mathrm{m}^{2}$ 'dir. Diş duvarlara ortadan yalıtım yapıldığında soğutma yükünde $(17,61$ $\mathrm{kWh} / \mathrm{m}^{2}$ ) çok az artış gerçekleşmiştir. İçten yalıtım yapıldığında ise $\left(17,78 \mathrm{kWh} / \mathrm{m}^{2}\right)$ diğer durumlara göre en fazla soğutma ihtiyacı ortaya çıkmaktadır (Şekil 5). Yol açtığı değişimler çok fazla olmamasına rağmen dış duvarlardaki yalıtım yerinin binalarda özellikle 1sıtma ve soğutma amaçlı enerji tüketiminde etkili olduğu göz ardı edilmemelidir.

Gece havalandırması yapıldığında, duvarlarda dıştan yalıtım ve hava hızı 2 ach olduğunda gece havalandırmasız duruma göre soğutma yükünün $\% 17,1$ daha az olduğu görülmüştür. Yalıtım yeri değiştirilip ortadan uygulandığında ise soğutma yükü \%17,06 azalmıştır. Yalıtım içten uygulandığında gece havalandırmasının performansı çok az azalmasına rağmen soğutma yükü $\% 16,42$ daha azdır. Hava hızı 4 ach olduğunda gece havalandırmasının soğutma yükünü daha da aşağıya çektiği görülmektedir. Yalıtım yerine bağlı olarak performans da ufak değişiklikler vardır. Yalıtım dıştan olduğunda soğutma yükü $\% 25,02$, ortadan olduğunda $\% 25,1$ ve içten olduğunda \%24,2 azalmaktadır.Hava hızı 6 ach olduğunda ise yalıtım dıştan uygulandığında soğutma yükü \%29,3, ortadan uygulandığında \%29,1 ve içten uygulandığında \%27,9 azalmaktadır.

2020'li yıllarda küresel 1sınmanın etkisine bağlı olarak soğutma yükünün arttığı görülmektedir. Baz yılla karşılaştırıldığında gece havalandırması yapılmadığı durumda soğutma yükü ortalama \%39 daha fazla olmaktadır. Gece havalandırması yapıldığı durumlarda yalıtım yeri ve hava hızına bağlı olarak soğutma yükü azalmaktadır. Duvarda dıştan yalıtım ve gece havalandırması hava hızı 2 ach olduğunda gece havalandırmasız durumla karşılaştırıldığında soğutma yükünün \%11,3 azaldığ1 görülmüştür (Şekil 6). Yalıtım ortadan uygulandığında soğutma yükü yine $\% 11,3$ oranında azalmıştır. Yalıtım içten uygulandığında ise gece havalandırmasının performansı azalmıştır buna rağmen soğutma yükü \%10,9 daha azdır. Hava hızı 4 ach olduğunda gece havalandırması ile soğutma yükü daha fazla azalmaktadır. Yalıtım dıştan uygulandığında soğutma yükü $\% 17,5$, ortadan uygulandığında $\% 17,4$ ve içten uygulandığında $\quad \% 16,8 \quad$ azalmaktadır.Gece havalandırması hava hızı 6 ach olduğunda ise diştanyalıtımda soğutma yükü $\% 20,9$, ortadan olduğunda $\% 20,7$ ve içten yalıtımda $\% 20$ daha azdır. 


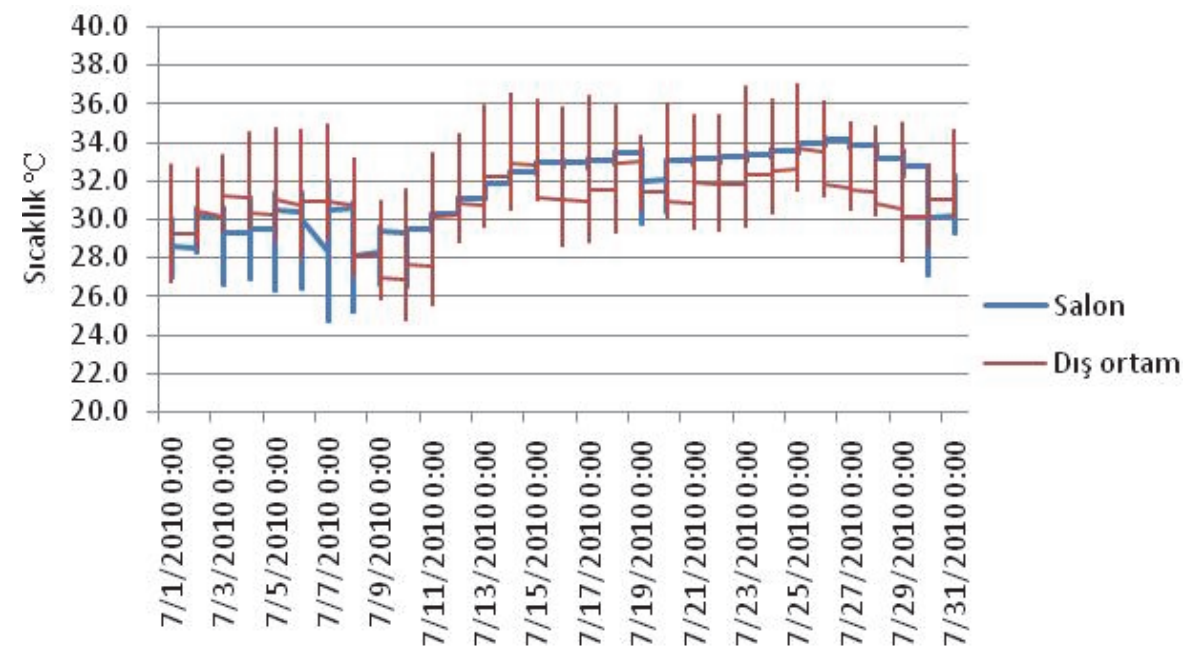

Şekil 4. Salon ile dış ortam sıcaklığının karşılaştırılması(Comparison of living room temperatures with outdoor temperatures)

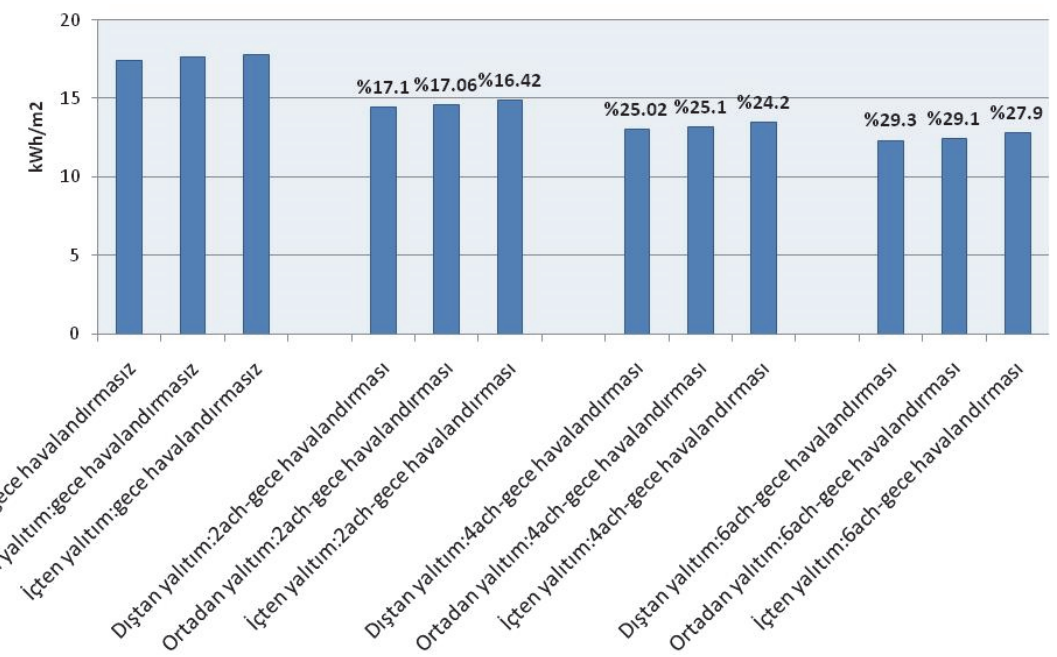

Şekil 5. Gece havalandırması performansına yalıtım yeri ve hava hızının etkisi-TMY2(The effect of insulation location and air flow rate on performance of night ventilation-TMY2)

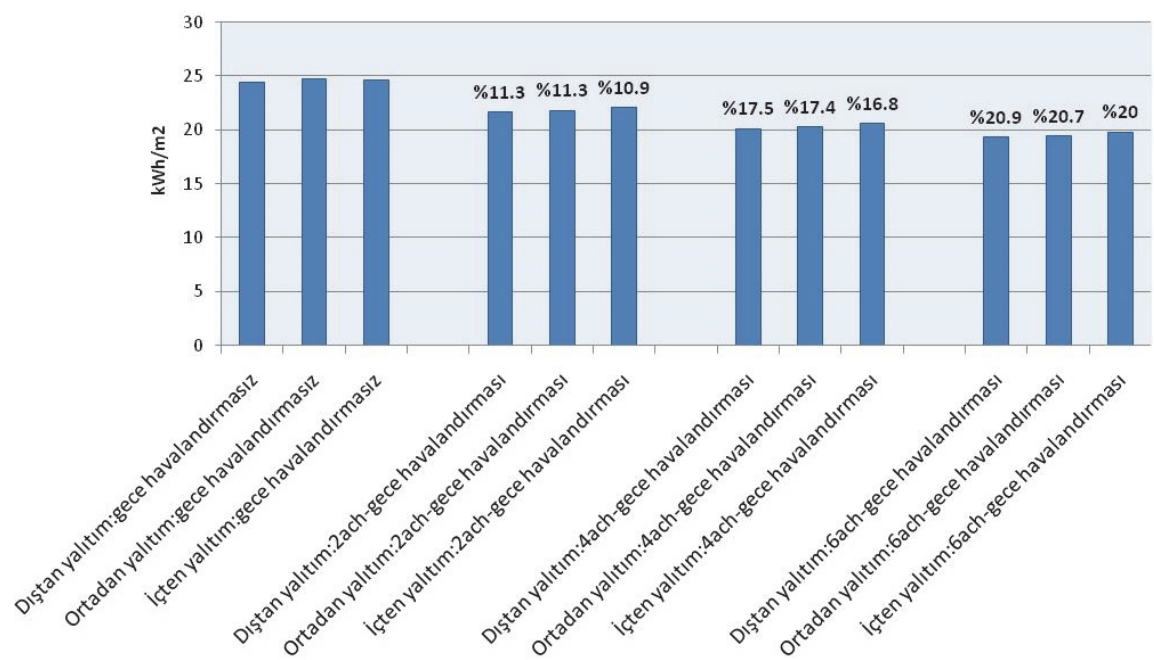

Şekil 6. Gece havalandırması performansına yalıtım yeri ve hava hızının etkisi-2020(The effect of insulation location and air flow rate on performance of night ventilation-2020s) 
2050’li yıllarda baz yılla karşıllaştırıldığında gece havalandırması yapılmadığı durumda soğutma yükü ortalama $\% 83$ daha fazladır. Gece havalandırması yapılması halinde, diştan ve ortadan yalıtım ve gece havalandırması hava hızı 2 ach olduğunda gece havalandırmasız duruma göre soğutma yükü \%6,9 azalmaktadır (Şekil 7). İçten yalıtım uygulandığında ise soğutma yükü $\% 6,6$ daha azdır. Gece havalandırması ile hava hızı 4 ach olduğunda soğutma yükü dahada düşmektedir. Dıştan yalıtımda \%11,2, ortadan yalıtımda $\% 11,1$ ve içten yalıtımda $\% 10,7$ soğutma yükü azalmaktadır.Hava hızı 6 ach olduğunda ise dıştan yalıtımda soğutma yükü \%13,7 ortadan olduğunda \%13,6 ve içten yalıtımda \%13,1 daha azdir.

Gece havalandırması yapılmadığı durumda, baz yılla karşılaştırıldığında 2080'li yıllarda, soğutma yükü ortalama 2,5 kat daha fazla olmaktadır. Gece havalandırması yapılması halinde, içten, ortadan ve dıştan yalıtımlı duvarda ve hava hızı 2 ach olduğunda soğutma yükü yaklaşık \%0,9 azalmaktadır (Şekil 8). Gece havalandırması hava hızı 4 ach olduğunda soğutma yükü ortalama $\% 3$, hava hızı 6 ach olduğunda ise soğutma yükü ortalama $\% 4,5$ düşmektedir.

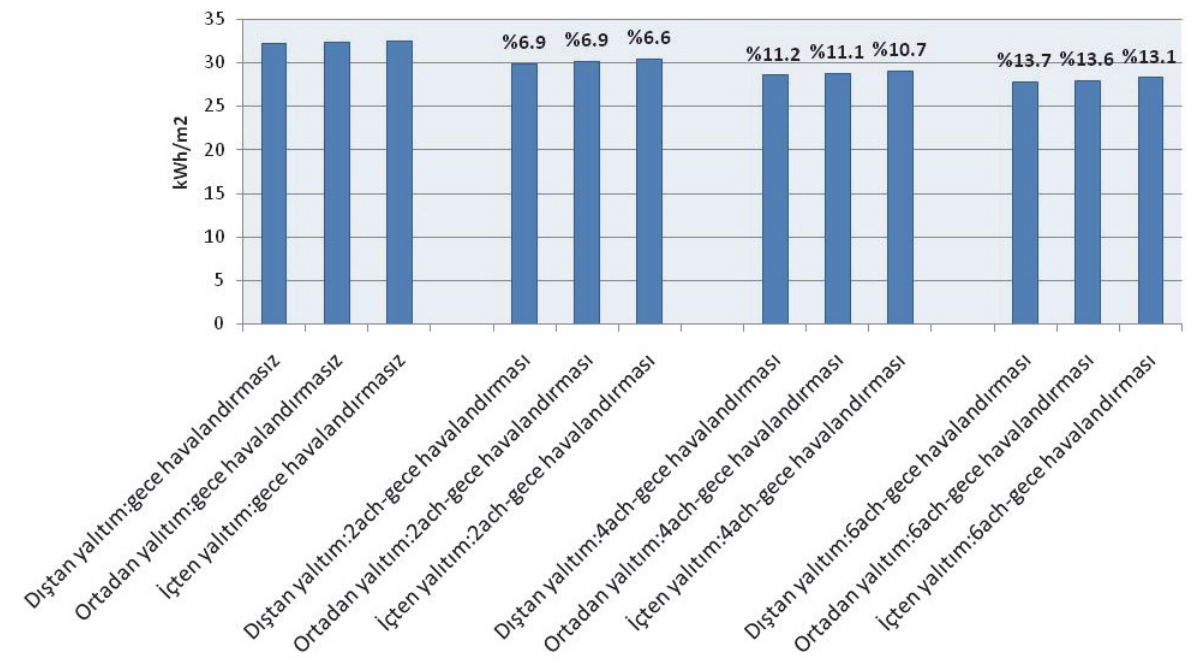

Şekil 7. Gece havalandırması performansına yalıtım yeri ve hava hızının etkisi-2050(The effect of insulation location and air flow rate on performance of night ventilation-2050)

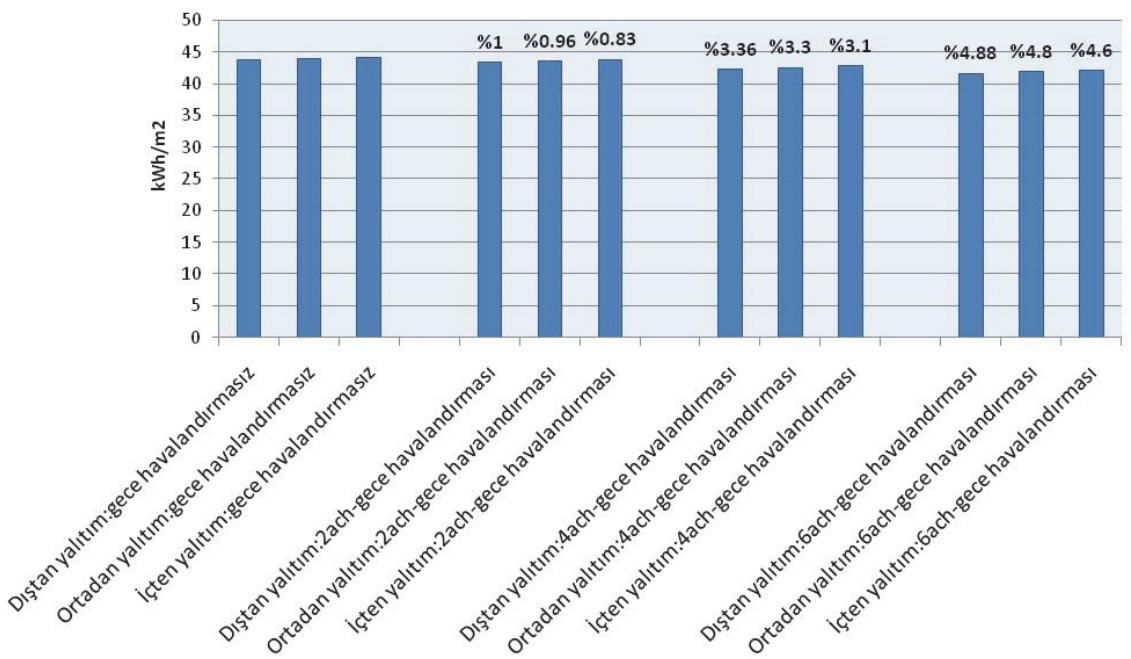

Şekil 8. Gece havalandırması performansına yalıtım yeri ve hava hızının etkisi-2080(The effect of insulation location and air flow rate on performance of night ventilation-2080)

\section{SONUÇLAR (CONCLUSIONS)}

$\mathrm{Bu}$ çalışmada, sıcak-nemli iklimlerde bulunan konutlarda gece havalandırmasının soğutma yükünü nasıl etkilediği ve performansının dış duvarlarda yalıtım yeri, hava hızı oranı ve iklim değişikliğine bağlı olarak nasıl değiștiği İzmir'de bulunan bir apartman binası kullanılarak detaylı şekilde incelenmiştir. Çalışmadan elde edilen ana sonuçlar aşağıdaki şekilde özetlenebilir:

- Sicak-nemli iklimlerde, soğutma amaçlı enerji tüketimi üzerinde dış duvarlardaki 
yalıtım yerinin etkisi olduğu görülmektedir. Enerji tüketimi açısından dış duvarlarda yalıtımın dıştan yapılması diğer durumlara göre daha avantajlıdır.

- Yalıtım yerinin gece havalandırması performans1 üzerinde, benzer oranda etkili olduğu görülmektedir. Gece havalandırması yaparak soğutma yükünü azaltmak için yalıtımın dıştan olması performansı arttırmaktadır. Bunun en önemli sebebi olarak isıl kütlenin etkisi gösterilebilir. Yalıtım diştan olduğunda gece havalandırması ile elde edilecek serinlik duvarda depolanabilir. Yalıtım içten yapıldığında serinliğin depolanacağı yüzey miktarı azalmakta ve elde edilen performans çok azda olsa düşmektedir. Ortadan yalıtım içten yalıtıma göre daha avantajlı olmasına rağmen en iyi performans dıştan yalıtım ile elde edilmektedir.

- Genel olarak bakıldığında, gece havalandırması hava değişim hızı oranı arttığında soğutma yükü önemli ölçüde azalmaktadır. Fakat hava hızının doğal yollarla arttırılması her zaman mümkün ve kolay olmamaktadır. Binanın bulunduğu yer, yönlenmesi ve binanın mimari özellikleri hava hızında kayda değer etkiye sahiptir. Mimari olarak açıklıkların/pencerelerin yatayda ve düşeyde yerleri ve büyüklükleri rüzgar yönü ve diğer binalarda dikkate alınarak hava değişim hızının artmasına olanak verecek şekilde tasarlanmalıdır. Yeterli hava hızı elde edilemediği durumlarda fan kullanılarak hibrid yaklaşım uygulanabilir.

- Küresel 1sınmanın gece havalandırması performansını nasıl etkileyebileceği incelenmiş, 2020'li yıllarda gece havalandırması ile soğutma yükünü ortalama \%16 azaltmak mümkün iken, 2080'li yıllarda sadece ortalama $\% 2,7$ azaltılabileceği görülmüştür. Küresel 1sınmanın etkilerine bağlı olarak, ortalama dış hava sıcaklıkları artmaktadır. Binaların ortalama ömrünün 50 yıl olduğu varsayıldığında enerji tüketimini azaltacak enerji etkin pasif ya da aktif önlemlerin performansının iklime bağlı değişimi incelenmeli ve etkili çözümler üretilmelidir. Sadece geçmiş iklim verilerini kullanarak karar vermenin her zaman yeterli olmayacağı ortaya konulmuştur.

Sonuç olarak, gece havalandırmasının sıcaknemli iklimlerdeki konutlarda soğutma yükünü azaltmak için kullanılabileceği, performansını etkileyen faktörlerle birlikte değerlendirilmiştir. En yüksek performansı elde etmek için diş duvarlarda dıştan yalıtım uygulanmalı ve hava değişim hızı en yüksek seviyeye çıkartacak pasif ve aktif çözümler üretilmelidir.

\section{KAYNAKLAR (REFERENCES)}

1. Guan, "Sensitivity of BuildingCoolingLoadstoFutureWeatherPredictio ns", ArchitecturalScienceReview, 54 (3), 178191, 2011.

2. Rajapaksha, U., Hyde, R., "BarrierstoandOpportunitiesfor Advanced PassiveCooling in Sub-tropicalClimates", ArchitecturalScienceReview， 55 (1), 49-60, 2012.

3. Waqas, A., Kumar, S., "Utilization of LatentHeat Storage UnitforComfortVentilation of Buildings in Hot andDryClimates", International Journal of GreenEnergy, 8 (1), 1-24, 2011.

4. Cunsulo, M.,Papparelli, A., Kurban, A., andMontilla, E., "TemporalEvolution of thePotential PassiveCoolingSystemsforAridAreas",

ArchitecturalScienceReview， 50 (1), 60-64, 2007.

5. Artmann, N.,Manz, H., andHeiselberg, P., "ClimaticPotentialforPassiveCooling of BuildingsbyNight-time Ventilation in Europe", AppliedEnergy, 84, 187-201, 2007.

6. Farisse, G.,Boichot, R., Kouyomji, J.-L., andSouyri, B., "NightCoolingwith a VentilatedInternalDouble Wall", EnergyandBuildings, 42, 393-400, 2010.

7. Artmann, N.,Manz, H., andHeiselberg, P., "ParameterStudy on Performance of BuildingCoolingbyNight-time Ventilation", RenewableEnergy, 33, 2589-2598, 2008.

8. Liping, W.,andHien, W.N., “Applying Natural VentilationforThermalComfort

ResidentialBuildings in Singapore", ArchitecturalScienceReview, 50 (3), 224-233, 2007.

9. Rotar, N.,andBadescu, V., "Considerations on theImplementation of thePassive House Concept in South-Eastern Europe (Romania)", International Journal of GreenEnergy, 8 (7), 780-794, 2011.

10. Geros, V.,Santamouris, M., Karatasou, S., Tsangrassoulis, A., andPapanikolaou, N., "On theCoolingPotential NightVentilationTechniques in teh Urban Environment", EnergyandBuildings, 37, 243257, 2005

11. Finn, D.,Connolly, D., andKenny, P., "Sensitivity Analysis of a MaritimeLocatedNightVentilated Library Building”, Solar Energy, 81, 697-710, 2007.

12. Artmann, N.,Gyalistras, D., Manz, H., andHeiselberg, P., "Impact of ClimateWarning on PassiveNightCoolingPotential", 
BuildingResearch\& Information, 36 (2), 1128, 2008.

13. Yun, G.Y.,andSteemers, K., "Night-Time NaturallyVentilatedOffices: $\quad$ Statistical Simulations of WindowusePatternsfromFieldMonitoring", Solar Energy, 84, 1216-1231, 2010.

14. Balaras, C.A., "The Role of ThermalMass on theCoolingLoad of Buildings: An Overview of ComputationalMethods", EnergyandBuildinsg, 24, 1-10, 1996.

15. Zhou, j.,Zhang, G., Lin, Y., andLi, Y., "Coupling of ThermalMassand Natural Ventilation in Buildings", EnergyandBuildinsg, 40, 979-986, 2008.

16. Yang, L., andLi, Y., "CoolingLoadReductionby Using ThermalMassandNightVentilation”, EnergyandBuildinsg, 40, 2052-2058, 2008.

17. Santamouris, M.,Sfakianaki, A., andPavlou, K., "On theEfficiency of NightVentilationTechniquesAppliedtoResidentia 1Buildings", EnergyandBuildinsg, 42, 13091313, 2010.

18. Kubato, T.,Chyee, D.T.H., andAhmad, S., "TheEffects of NightVentilationTechniques on IndoorThermal Environment forResidentialBuildings in Hot-humidClimate of Malaysia”, EnergyandBuildings, 41, 829-839, 2008.

19. Ozel, M.,andPihtili, K., "Optimum Locationand Distribution of InsulationLayers on BuildingWallswithVariousOrientations",

Buildingand Environment, 42, 3051-3059, 2007.

20. Council of AmericanBuildingOfficals, The Model EnergyCode, Council of AmericanBuildingOfficals, 1995.
21. Henninger, R.H.,Witte, M.J., Carwley, D.B., "AnalyticalandComparativeTesting of EnergyPlus Using IEA HVAC BESTEST E100E200 Test Suite", EnergyandBuildings, 36, 855-863, 2004.

22. ASHRAE, AddendumtoThermal Environment Conditionsfor Human Occupancy, ANSI/ASHRAE Standard 55a-1995, 1995.

23. Meteoroloji Genel Müdürlüğü, http://www.dmi.gov.tr, (Erişim tarihi: 12 Şubat 2012).

24. Marion, W., and Urban, K., 'User's Manual for TMY 2 s. NationalRenewableEnergyLaboratory, USA: Golen, 1995.

25. Johns, T.C., et al., "AnthropogenicClimateChangefor "1860-2100 Simulatedwith HadCM3 Model Under UpdatedEmissionsScenarios", Climate Dynamics, 20, 583-612, 2003.

26. Nakicenovic, N., et al., Special Report on EmissionsScenarios: A Special Report of WorkingGroup III of theIntergovernmental Panel on ClimateChange", http://www.grida.no/climate/ipcc/emission/index .html, 2000, (Erişim tarihi: 12 Mart 2011).

27. Jentsch, F.M.,Bahaj, A.S., James, P.A.B., "ClimateChangeFuture Proofing of BuildingsGenerationandAssessment of BuildingSimulationWeatherFiles", EnergyandBuildings, 40, 2148-2168, 2008.

28. Belcher, S.E., Hacker, J.N., Powell, D.S., "Constructing Design Weather Data forFutureClimates", Building Services EngineeringResearchandTechnology, 26 (1), 49-61, 2005. 
